\title{
Histopathological study of non-infectious papulosquamous lesions of skin
}

\author{
Kartik Chabbi', Susmitha MS², Anupama YG ${ }^{3}$, Dadapeer HJ $^{4}$, Ramesh Babu K ${ }^{5}$ \\ ${ }^{1}$ Senior Resident, Department of Pathology, Subbaiah Institute of Medical Sciences, Shivamogga, ${ }^{2}$ Associate \\ Professor, ${ }^{5}$ Professor and Head, Department of Pathology, ${ }^{3}$ Associate Professor, ${ }^{4}$ Professor and Head, \\ Department of Dermatology, Shimoga Institute of Medical Sciences, Shivamogga, Karnataka, India
}

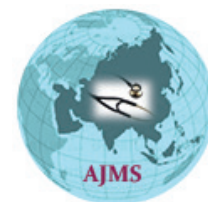

A B S T R A C T

Background: Papulosquamous diseases are characterized by scaly papules and plaques with similar clinical picture which leads to diagnostic confusion. A definitive histopathological diagnosis is required for effective treatment of such diseases. Aims and Objectives: The aim of the study was to study the clinicohistopathological correlation of different non-infectious papulosquamous skin lesions. Materials and Methods: Skin punch biopsy specimens from 100 clinically diagnosed/suspected non-infectious papulosquamous skin diseases were received in the Department of Pathology at a tertiary care hospital. The specimens obtained were subjected to formalin fixation and paraffin embedding, stained with hematoxylin and eosin and studied. Results: A total of 100 cases were studied. The most common lesion was psoriasis (42) followed by lichen planus (40). Maximum numbers of cases were seen in the age group of $31-60$ years $(61 \%)$. Males $(54 \%)$ were commonly affected. Positive clinicopathological correlation was observed in $85 \%$ cases. Conclusion: Contribution of histopathology is definitely significant in overcoming clinical diagnostic dilemma in certain papulosquamous disorders.

Key words: Histopathology; Papulosquamous; Psoriasis; Skin

\section{Access this article online}

Website:

http://nepjol.info/index.php/AJMS DOI: 10.3126/ajms.v13i3.42238

E-ISSN: 2091-0576

P-ISSN: 2467-9100

Copyright (c) 2022 Asian Journal of Medical Sciences

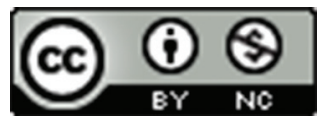

This work is licensed under a Creative Commons Attribution-NonCommercial 4.0 International License.

\section{INTRODUCTION}

A detailed clinical history and proper clinical examination are essential for the diagnosis of skin lesions. The diagnosis is made by considering distribution, color, type, and arrangement of lesions. Although the visibility of skin allows a quick and definitive diagnosis in some cases, similar clinical presentation often leads to diagnostic dilemma. ${ }^{1}$ Histopathological examination of skin lesion is an important diagnostic ancillary technique for the management of patients with skin disorders. The correlation of clinical diagnosis with the histopathological findings is not only of diagnostic help, but also aids in understanding of the mechanisms of skin diseases. Even in those cases where exact diagnoses cannot be made in histopathology, it can contribute by ruling out certain diagnoses. ${ }^{2,3}$
Papulosquamous diseases are frequently encountered group of diseases in dermatology and are characterized by scaly papules or plaques. Non-infectious papulosquamous skin lesions constitute about $24-25 \%$ of all the nonneoplastic skin lesions. ${ }^{4,5}$ Papulosquamous diseases include common conditions such as psoriasis and Lichen planus and also rare conditions such as parapsoriasis, pityriasis rosea, lichen nitidus, pityriasis rubra pilaris, and lichen striatus. Few of these papulosquamous conditions present with numerous clinical variants and mimic various dermatological conditions. This leads to a diagnostic dilemma for the clinician. Adverse reactions to many drugs may produce papulosquamous eruptions. Hence, many dermatoses need to be included in the differential diagnosis of a papulosquamous eruption. Clinical with histomorphological correlation and a definitive histopathological diagnosis are essential as treatment and

Address for Correspondence:

Dr. Susmitha MS, Associate Professor, Department of Pathology, Shimoga Institute of Medical Sciences, Shivamogga - 577201 ,

Karnataka, India. Mobile: +91-9480575724. E-mail: drsusmithams@gmail.com 
prognosis varies. ${ }^{6-8}$ As it is crucial to identify and classify these lesions, the present study was undertaken to study the age, sex distribution and histopathological spectrum of non-infectious, and papulosquamous skin diseases with clinicohistopathological correlation.

\section{Aims and objectives}

The objectives of the study are as follows:

1. To study the histopathological features of noninfectious papulosquamous lesions of skin.

2. To study clinicopathological correlation of noninfectious papulosquamous lesions of skin.

\section{MATERIALS AND METHODS}

The present study was conducted in Department of Pathology, Shimoga Institute of Medical Sciences, Shivamogga, from September 2017 to May 2019. The study was conducted after approval by Institutional Ethical Committee. One hundred cases of clinically diagnosed or suspected non-infectious papulosquamous skin lesions were identified. Skin punch biopsy was done after taking informed consent, in the Department of Dermatology. Before proceeding with the biopsy, local anesthesia was obtained by infiltration of $2 \%$ lignocaine solution under the lesion. The punch was pushed into the skin with a downward twisting movement, and then removed. The tissue specimen was lifted and separated from the underlying tissue, and removed from the biopsy punch. The wound was left to heal without suturing. Biopsy was placed in 10\% formalin and labeled. In the pathology department, punch biopsy samples were fixed in 10\% formalin. After routine processing and embedding, paraffin blocks were prepared. 4-6 $\mu$ thick sections were obtained and stained with hematoxylin and eosin staining. Detailed histopathological examination was done.

\section{RESULTS}

In the present study, out of 100 cases 42 cases were diagnosed as psoriasis followed by lichen planus (40 cases), lichen planus pigmentosus (four cases), pityriasis rubra pilaris (three cases), hypertrophic lichen planus (two cases), and one case each of prurigo nodularis, lichen planopilaris, pityriasis rosea, lichen nitidus, PLEVA, pustular psoriasis, and lichenoid drug eruption. Two cases were inconclusive (Table 1). Maximum number of cases $(61 \%)$ were seen in the age group of 31-60 years. Males (54\%) were commonly affected. Positive clinicopathological correlation was observed in $85 \%$ cases (Table 2).

Of the 42 cases histopathologically diagnosed cases of psoriasis (Figures 1 and 2), 40 cases (95.23\%) were

\begin{tabular}{|c|c|c|}
\hline Disease & Cases (n) & Percentage \\
\hline Psoriasis & 42 & 42 \\
\hline Pustular psoriasis & 01 & 1 \\
\hline Lichen planus & 40 & 40 \\
\hline Lichen planus pigmentosus & 04 & 04 \\
\hline Hypertrophic lichen planus & 02 & 02 \\
\hline Lichen planopilaris & 01 & 01 \\
\hline Pityriasis rubra pilaris & 03 & 03 \\
\hline Prurigo nodularis & 01 & 01 \\
\hline Pityriasis rosea & 01 & 01 \\
\hline Lichen nitidus & 01 & 01 \\
\hline PLEVA & 01 & 01 \\
\hline Lichenoid drug eruption & 01 & 01 \\
\hline Inconclusive & 02 & 02 \\
\hline Total & 100 & 100 \\
\hline
\end{tabular}

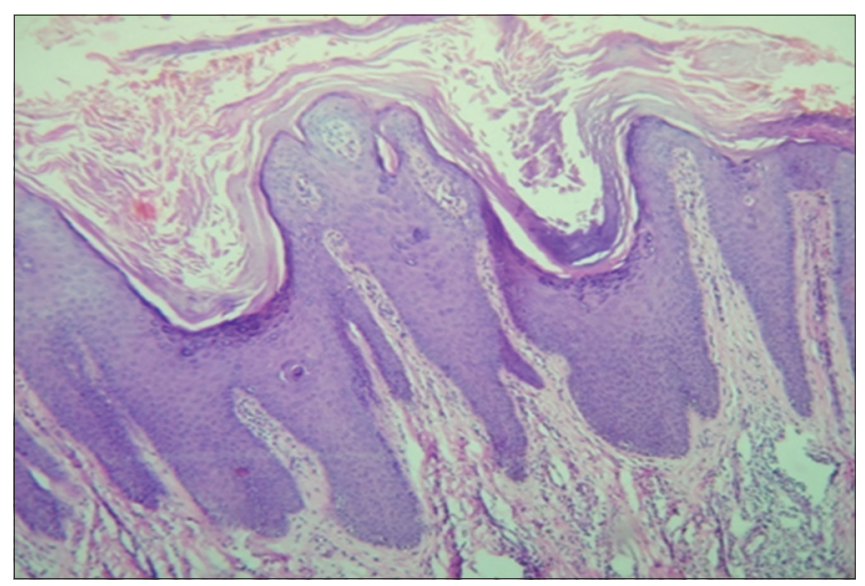

Figure 1: Psoriasis showing hyperkeratosis and elongated rete ridges (H\&E, $\times 100)$

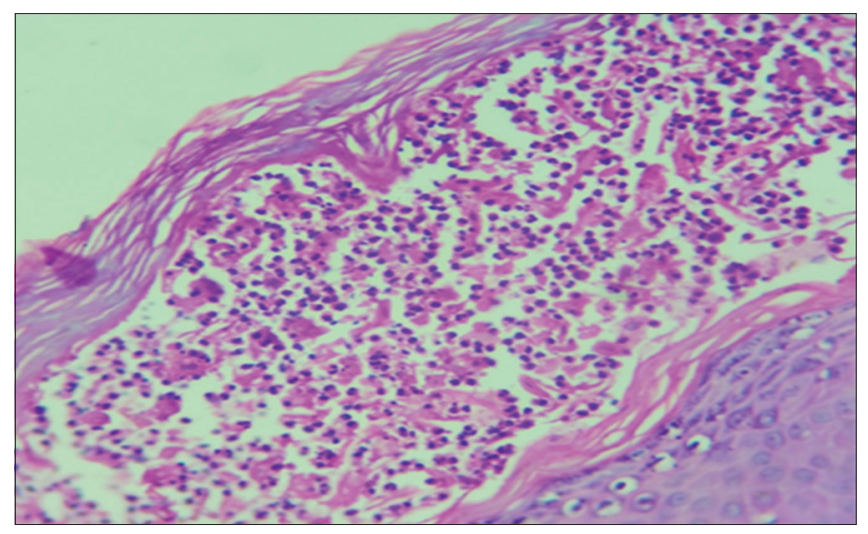

Figure 2: Pustular psoriasis with macroabscess (H\&E, $\times 100)$

clinically suspected/diagnosed as psoriasis and were concordant. Two cases $(4.8 \%)$ presented clinically as phytophotodermatitis. One case of histopathologically diagnosed pustular psoriasis was concordant $(100 \%)$ with clinical diagnosis.

Forty cases were histopathologically diagnosed as lichen planus (Figure 3), of which 34 cases $(85 \%)$ were clinically 


\begin{tabular}{|c|c|c|c|}
\hline Disease (n) & $\begin{array}{l}\text { Clinical } \\
\text { diagnosis }\end{array}$ & $\begin{array}{c}\text { Concordance with } \\
\text { histopathological diagnosis }\end{array}$ & $\begin{array}{c}\text { Discordance with } \\
\text { histopathological diagnosis }\end{array}$ \\
\hline Psoriasis (42) & 40 & $40(95.23 \%)$ & $02(4.8 \%)$ \\
\hline Pustular psoriasis (1) & 01 & $01(100 \%)$ & $00 \%$ \\
\hline Lichen planus (40) & 34 & $34(85 \%)$ & $06(15 \%)$ \\
\hline Lichen planus pigmentosus (4) & 04 & $04(100 \%)$ & $00 \%$ \\
\hline Hypertrophic lichen planus (2) & 01 & $01(50 \%)$ & $01(50 \%)$ \\
\hline Lichen planopilaris (1) & 00 & $00 \%$ & $01(100 \%)$ \\
\hline Pityriasis rubra pilaris (3) & 01 & $01(33.3 \%)$ & $02(66.6 \%)$ \\
\hline Prurigo nodularis (1) & 01 & $01(100 \%)$ & $00 \%$ \\
\hline Pityriasis rosea (1) & 01 & $01(100 \%)$ & $00 \%$ \\
\hline Lichen nitidus (1) & 00 & $00 \%$ & $01(100 \%)$ \\
\hline PLEVA (1) & 01 & $01(100 \%)$ & $00 \%$ \\
\hline Lichenoid drug eruption (1) & 01 & $01(100 \%)$ & $00 \%$ \\
\hline Inconclusive (2) & - & - & - \\
\hline Total $(100)$ & 85 & $85(85 \%)$ & $13(13 \%)$ \\
\hline
\end{tabular}

suspected/diagnosed and were concordant and six cases $(15 \%)$ of them had different clinical diagnosis.

Four cases of histopathologically diagnosed lichen planus pigmentosus were concordant (100\%) with clinical diagnoses. Two cases were histopathologically diagnosed as hypertrophic lichen planus (Figure 4), of which 1 case $(50 \%)$ was concordant with clinical diagnosis. The other case clinically presented as psoriasis. One case of histopathologically diagnosed lichen planopilaris (Figure 5) had different clinical diagnosis (100\%), which clinically presented as psoriasis. Three cases were histopathologically diagnosed as pityriasis rubra pilaris, of which 1 case $(33.3 \%)$ was clinically suspected and was concordant and 2 cases $(66.6 \%)$ clinically presented as psoriasis.

One case each of histopathologically diagnosed prurigo nodularis, pityriaisis rosea (Figure 6), PLEVA, and lichenoid drug reaction was concordant with clinical diagnoses. One case of histopathologically diagnosed lichen nitidus had different clinical diagnosis. Two cases were inconclusive.

A concordance between clinical diagnosis and histopathological diagnosis was observed in $85 \%$ of the cases and a discordance of $13 \%$ was seen. Hence, histopathology confirmed the diagnosis in 85\% and it gave the diagnosis in 13\% cases.

\section{DISCUSSION}

Papulosquamous diseases are usually characterized by scaling papules and plaques. This leads to lot of confusion in clinical diagnosis, and hence, a definitive histopathological diagnosis aids in the treatment of such diseases. ${ }^{9,10}$

In the present study, psoriasis was the most common disease accounting for $42 \%$. The finding was similar to that

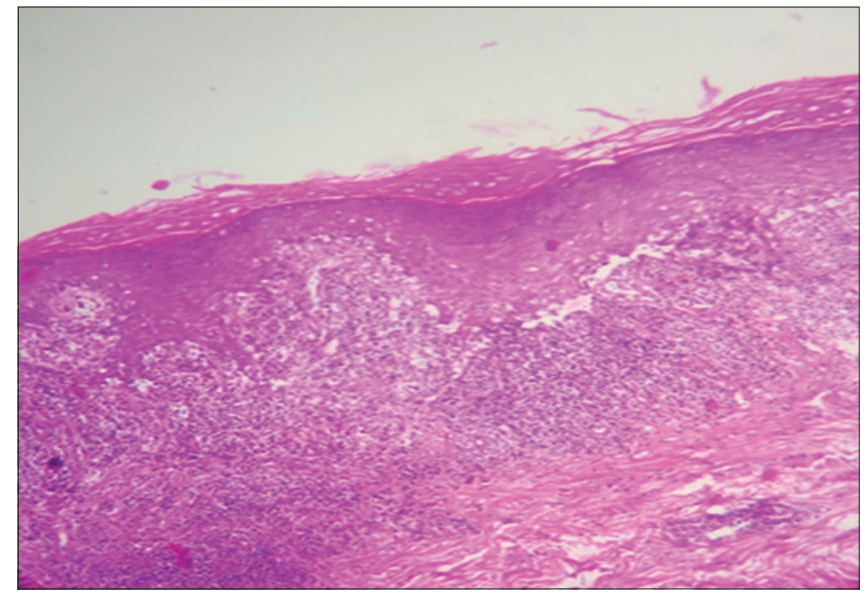

Figure 3: Hyperkeratosis, hypergranulosis, and band like lymphocytic infiltration in lichen planus $(H \& E, \times 100)$

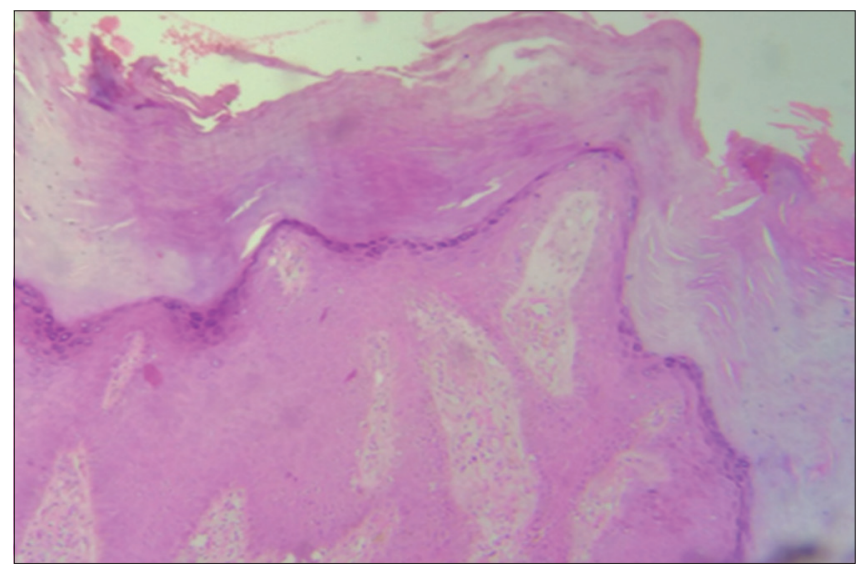

Figure 4: Hypertrophic lichen planus $(H \& E, \times 100)$

in studies done by Chavhan et al., ${ }^{11}$ and Narayankar and Pandit ${ }^{12}$ in which psoriasis accounted to $32.7 \%$ and $42 \%$, respectively. The highest incidence was seen $5^{\text {th }}$ decade. Kumari, ${ }^{13}$ D'Costa, and Bharambe ${ }^{14}$ reported the highest number of cases in $3^{\text {rd }}$ and $4^{\text {th }}$ decade, respectively. In our study, male preponderance $(63 \%)$ was seen which 
were concordant with the studies done by Younas and Haque $^{5}$ (78.57\%). and Agrawal et al., ${ }^{1}$ (66.6\%).

The characteristic primary lesion of these disorders is a papule, usually erythematous, that has a variable amount of scaling on the surface. Plaques or patches form through coalescence of the primary lesions, which most commonly appear on the elbows, knees, scalp, umbilicus, and lumbar area. ${ }^{12,15}$ In the present study, the most common sites of lesion were all over the body followed by limbs, scalp, and groin.

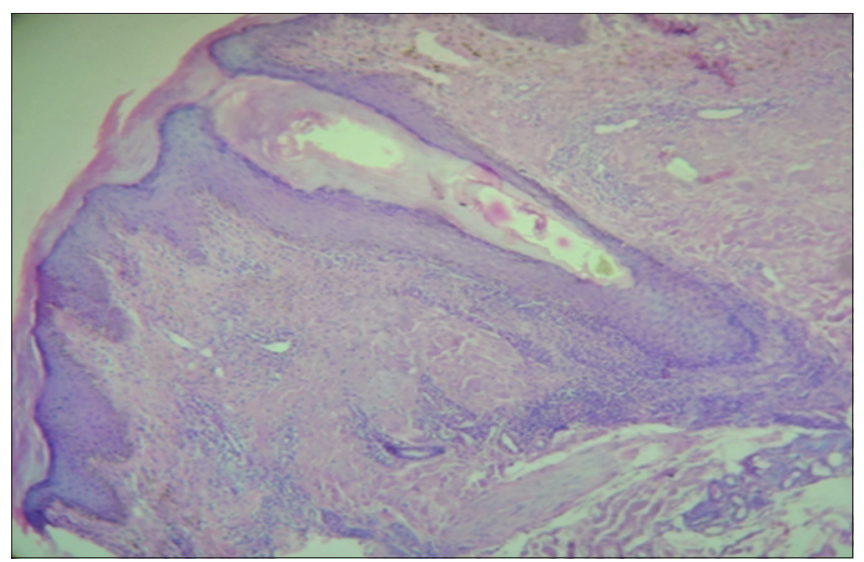

Figure 5: Lichen planopilaris showing perifollicular inflammation $(H \& E, \times 100)$

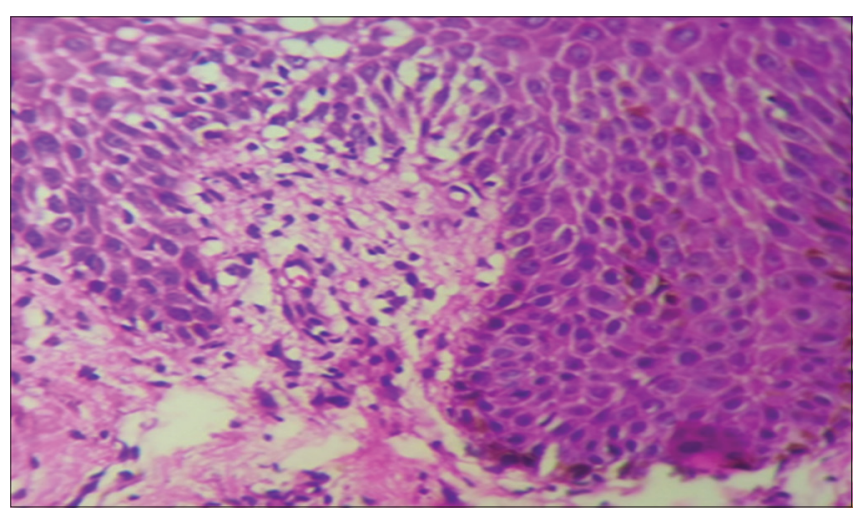

Figure 6: Pityriasis Rosea with lymphocytic exocytosis (H\&E, $\times 400)$
The most frequent histopathological findings were hyperkeratosis, parakeratosis, acanthosis, suprapapillary thinning, elongation of the rete ridges, Munro's micro abscesses, dermal lymphocytic infiltration, and vascular changes. The studies done by Jayalakshmy et al., ${ }^{16}$ Kumari, ${ }^{13}$ Barman et al., ${ }^{9}$ and Karumbaiah et al., ${ }^{15}$ showed similar findings with varying percentage (Table 3 )

In the present study, one case of pustular psoriasis was seen in a male patient aged 62 years. He presented with scaly lesions and pustules. The study done by Kumari ${ }^{13}$ showed $12 \%$ pustular psoriasis.

In the present study, lichen planus was the second most common disease accounting for $40 \%$. Similar findings were observed in studies done by Balaji et al., ${ }^{7}$ and Saritha et al., ${ }^{6}$ in which it accounted to $47.2 \%$ and $48.84 \%$, respectively. The highest incidence was seen in $4^{\text {th }}$ decade. Lichen planus had equal sex distribution which was concordant with study done by Narayankar and Pandit, ${ }^{12}$ Karumbaiah et al., ${ }^{15}$ and Chavhan et al., ${ }^{11}$ reported maximum number of cases in males. The most of the patients presented as multiple violaceous and hyperpigmented papules. The common sites of lesion were arms and legs followed by all over the body. In the present study, the histopathology of lichen planus showed hyperkeratosis, focal parakeratosis, hypergranulosis, acanthosis, vacuolar degeneration of basal cell, Max-Joseph space, Civatte body, band like infiltrate, lymphocytic infiltration, and pigment incontinence. These findings were similar to that of studies by Karumbaiah et al., ${ }^{15}$ Chavhan et al., ${ }^{11}$ and Barman et al. ${ }^{9}$ Civatte bodies were more frequently observed in the present study (Table 4).

In the present study, lichen planus pigmentosus was the third most common disease accounting for $4 \%$ which was similar to studies done by Gurusamy and Selvaraj et al., ${ }^{17}$ and Deepti et al. ${ }^{18}$ The most of the cases were between $3^{\text {rd }}$ and $4^{\text {th }}$ decade according to studies done by Kanwar et al. ${ }^{19}$ and Mathews et al. ${ }^{20}$ In the present study, lichen

\begin{tabular}{|c|c|c|c|c|c|}
\hline Histopathological findings & $\begin{array}{l}\text { Present } \\
\text { study (\%) }\end{array}$ & $\begin{array}{c}\text { Jayalakshmy } \\
\text { et al. }{ }^{16}(\%)\end{array}$ & Kumari $^{13}(\%)$ & $\begin{array}{l}\text { Barman } \\
\text { et al. }{ }^{9}(\%)\end{array}$ & $\begin{array}{c}\text { Karumbaiah } \\
\text { et al. }{ }^{15}(\%)\end{array}$ \\
\hline \multicolumn{6}{|l|}{ Epidermal changes } \\
\hline Hyperkeratosis & 100 & 25 & 82 & 77 & 77.27 \\
\hline Parakeratosis & 95.24 & 100 & 100 & 88.88 & 72.72 \\
\hline Hypogranulosis & 50 & 97.5 & 84 & 44.44 & 22.72 \\
\hline Acanthosis & 76.19 & 100 & 98 & 88.88 & 86.36 \\
\hline Elongated rete ridges & 69.04 & 90 & 96 & - & 72.72 \\
\hline Munro microabscess & 66.67 & 87.5 & 44 & 44.44 & 22.72 \\
\hline Spongiform pustule of Kogoj & 19.04 & 12.5 & 20 & - & 4.54 \\
\hline Suprapapillary thinning & 80.95 & 100 & 86 & 66.66 & 40.90 \\
\hline \multicolumn{6}{|l|}{ Dermal changes } \\
\hline Lymphocytic infiltration & 100 & 100 & 100 & 88.88 & 81.81 \\
\hline Vascular changes & 71.43 & 95 & 100 & 88.88 & 86.36 \\
\hline
\end{tabular}




\begin{tabular}{|c|c|c|c|c|}
\hline Histopathological findings & $\begin{array}{l}\text { Present } \\
\text { study (\%) }\end{array}$ & $\begin{array}{c}\text { Karumbaiah } \\
\text { et al. }{ }^{15}(\%)\end{array}$ & $\begin{array}{l}\text { Chavhan } \\
\text { et al. }{ }^{11}(\%)\end{array}$ & $\begin{array}{c}\text { Barman } \\
\text { et al. }{ }^{9}(\%)\end{array}$ \\
\hline \multicolumn{5}{|l|}{ Epidermal changes } \\
\hline Hyperkeratosis & 100 & 100 & 29 & 70.83 \\
\hline Hypergranulosis & 95 & 76.47 & 89 & 58.33 \\
\hline Acanthosis & 92.5 & 76.47 & 66 & 70.83 \\
\hline Vacuolar degeneration of basal cell & 100 & 100 & 83 & 81.33 \\
\hline Max-Joseph space & 17.5 & 23.52 & 6 & 4.16 \\
\hline Civatte body & 27.5 & 11.76 & 6 & - \\
\hline \multicolumn{5}{|l|}{ Dermal changes } \\
\hline Band like infiltrate & 75 & 76.47 & 89 & \\
\hline Lymphocytic infiltration & 100 & 100 & 100 & 91.6 \\
\hline Pigment incontinence & 20 & - & 49 & 54.16 \\
\hline
\end{tabular}

planus pigmentosus showed varied presentation in age group, all the four were females. Similarly, the studies done by Mathews et al., ${ }^{20}$ and Bhat et al., ${ }^{21}$ showed female preponderance.

In the present study, lichen planus pigmentosus presented with hyperpigmented macule/patch predominantly over the face followed by back and thigh. All cases showed epidermal thinning, basal cell degeneration, and pigment incontinence. In the present study, hypertrophic lichen planus accounted for $2 \%$. It was seen in $2^{\text {nd }}$ and $4^{\text {th }}$ decade with equal sex distribution. The studies done by Kaur et al., ${ }^{10}$ Parihar and Sharma, ${ }^{22}$ Ankad and Beergouder, ${ }^{23}$ Raghavendra, and Basha ${ }^{24}$ showed male preponderance. Histological changes were acanthosis, hypergranulosis, and compact orthokeratosis and most common site was lower limbs.

Pityriasis rubra pilaris accounted for 3\% which was similar to studies done by Agrawal et al., ${ }^{1}$ Karumbaiah et al., ${ }^{15}$ and Narayankar and Pandit, ${ }^{12}$ in which it accounted to $6 \%$, $4 \%$, and $3 \%$, respectively. In the present study, pityriasis rubra pilaris were seen in males and in $4^{\text {th }}$ and $5^{\text {th }}$ decade. It presented with scaly patches and plaques. Study done by Gerharz et al., ${ }^{25}$ showed bimodal age distribution pattern with peak incidences in the $1^{\text {st }}$ and $5^{\text {th }}$ decade. Histological findings were acanthosis with broad and short rete ridges, alternating orthokeratosis and parakeratosis with focal hypergranulosis.

In the present study, one case of pityriasis rosea was seen in a female patient in $3^{\text {rd }}$ decade. She presented with scaly patch and histopathology showed hyperkeratosis, hypogranulosis, acanthosis, spongiosis, parakeratosis, lymphocytic exocytosis, and extravasated erythrocytes in the dermis.

In the present study, one case each of prurigo nodularis, lichen planopilaris, lichen nitidus, lichenoid drug eruptions, and PLEVA was present.

\begin{tabular}{lc}
$\begin{array}{l}\text { Table 5: Clinical and histopathological } \\
\text { correlation in various studies }\end{array}$ \\
\hline Study & Correlation \\
\hline Barman et al. $^{9}$ & $92 \%$ \\
Kaur et al. ${ }^{10}$ & $74 \%$ \\
Raju et al. & \\
Balaji et al. & \\
Agrawal et al. & \\
Present study & $68.72 \%$ \\
\end{tabular}

Overall clinicopathological concordance of papulosquamous skin lesions of in our study was $85 \%$. The study done by Barman et al., ${ }^{9}$ had higher percentage of correlation of $92 \%$ whereas Kaur et al., ${ }^{10}$ Raju et al., ${ }^{26}$ Balaji et al., ${ }^{7}$ and Agrawal et al. ${ }^{1}$ had lower clinical and histopathological correlation of $74 \%, 68.72 \%, 62.96 \%$, and $58 \%$, respectively (Table 5).

\section{Limitations of the study}

It was a single centre study. Multi - centre studies involving wider population need to be conducted to study the wide clinical and histopathological spectrum of papulosquamous skin lesions.

\section{CONCLUSION}

The clinical pattern and histological features of papulosquamous skin disorders overlap. In such circumstances attempting a conclusive histopathological diagnosis by clinicopathological correlation serves as an ideal approach. Contribution of histopathology is definitely significant in overcoming clinical diagnostic dilemma in certain cases. As the papulosquamous disorders are commonly encountered dermatological conditions, we emphasize the role of clinicopathological correlation for accurate diagnosis, which aids in appropriate and effective clinical management and better clinical outcome.

\section{ACKNOWLEDGMENT}

We thank the technical and nursing staff for their support. 


\section{REFERENCES}

1. Agrawal S, Mishra KB and Gupta CM. Histopathological spectrum of non-infectious erythematous, papulo-squamous lesions: At a tertiary care institute. Int J Res Med Sci. 2018;6(6):2072-2075. https://doi.org/10.18203/2320-6012.ijrms20182291

2. Elder DE, Murphy GF, Elinitsas R, Johnson $B L$ and $X u X$. Introduction to dermatopathologic diagnosis. In: Lever's Histopathology of the Skin. $10^{\text {th }}$ ed. New Delhi: Wolters Kluwer; 2009. p. 1-4.

3. Calonje E. Histopathology of the skin: General principles. In: Burns T, Breathnach S, Cox N and Griffiths C, editors. Rook's Textbook of Dermatology. $8^{\text {th }}$ ed. United Kingdom: Blackwell; 2010. p. 10.1-10.43.

4. Rajput JS, Singh K, Singh S and Amarjeet S. Clinicopathological study of non neoplastic skin disorders. MedPulse Int Med J. 2014;1(8):367-372.

5. Younas M and Haque AU. Spectrum of histopathological features in non infectious erythematous and papulosquamous diseases. Int J Pathol. 2004;2(1):24-30.

6. Saritha C, Unissa A and Anil S. A clinico-histopathological study on papulosquamous skin lesions-tertiary care hospital. GJRA. 2018;7(1):8-11.

7. Balaji C, Parvathi M, Kumar SS, Lekha GD, Lavanya L, Lahari MV, et al. Clinicopathological study of papulosquamous skin lesions. J Evid Based Med Healthc. 2018;5(8):699-704.

8. Fox BJ, Odom RB and Francisco $S$. Education papulosquamous diseases: A review. J AmAcadDermatol.1985;12(4):597-624. https://doi.org/10.1016/s0190-9622(85)70084-9

9. Barman DD, Bhattacharyya P, Ray PS, Sarkar S, Sarkar R and Roy AK. Clinicopathological correlation of noninfectious erythematous papulosquamous cutaneous lesions in a tertiary care hospital. Indian J Dermatopathol Diagn Dermatol. 2018;5:101-105.

https://doi.org/10.4103/ijdpdd.ijdpdd_21_17

10. Kaur G, Chahal KS and Maklhotra SK. Clinicopathological correlation of non infectious erythematous papulosquamous lesions of skin. J Adv Med Dent Sci Res. 2019;7(2):131-135. https://doi.org/10.21276/jamdsr

11. Chavhan SD, Mahajan SV and Vankudre AJ. A descriptive study on patients of papulosquamous lesion at tertiary care institute. MVP J Med Sci. 2014;1(1):30-35.

https://doi.org/10.15306/mvpjms/2014/v1i1/46888

12. Narayankar SL and Pandit GA. Papulosquamous: Clinicopathological. Int J Res Med Sci.2018;6:309-316. https://doi.org/10.18203/2320-6012.ijrms20175740

13. Kumari KM. Psoriasis and significance of clinicopathological correlation in a tertiary care hospital. Arch Cytol Histopathol Res. 2017;2(2):23-26.
14. D'Costa G and Bharambe BM. Spectrum of noninfectious erythematous, papular and squamous lesions of the skin. Indian J Dermatol. 2010;55(3):225-228. https://doi.org/10.4103/0019-5154.70666

15. Karumbaiah KP, Anjum A and Mallikarjun M. A histopathologic study of papulosquamous lesions of skin. Indian J Pathol. 2017;6(2):404-409. https://doi.org/10.21088/ijprp.2278.148X.6217.11

16. Jayalakshmy PL, Babitha AM, Sankar S and Nandakumar G. Histopthological spectrum of psoariasiform dermatitis. J Pathol Nepal. 2016;6:975-980. https://doi.org/10.3126/jpn.v6i12.16265

17. Guruswamy L and Selvaraj U. Clinicopathological study of lichen planus in a tertiary care center. Int J Sci Study. 2016;4(1):244-247. https://doi.org/10.17354/ijss/2016/225

18. Deepti S, Milind $P$, As $R$ and Sarang W. Clinical and histopathological study of lichen planus. J Cont Med A Dent. 2017;5(1):54-57.

19. Kanwar AJ, Dogra S, Handa S, Parsad D and Radotra BD. A study of 124 Indian patients with lichen planus pigmentosus. Clin Exp Dermatol. 2016;28:481-485. https://doi.org/10.1046/j.1365-2230.2003.01367.x

20. Mathews I, Thappa DM, Singh $N$ and Gochhait D. Lichen planus pigmentosus: A short review. Pigment Int. 2016;3:5-10. https://doi.org/10.4103/2349-5847.184265

21. Bhat RM, Maathanda TR, Jayaprakash CS and Dandakeri S. Clinical, histopathological charecteristics and immunohistochemical findings in lichen planus pigmentosus. Indian J Dermatol. 2017;62:612-617. https://doi.org/10.4103/ijd.IJD_148_17

22. Parihar A and Sharma S. A clinicopathological study of cutaneous lichen planus. J Saudi Soc Dermatol Dermatol Surg. 2014;19(1):10-15. https://doi.org/10.1016/j.jssdds.2013.12.003

23. Ankad BS and Beergouder SL. Hypertrophic lichen planus versus prurigo nodularis: A dermoscopic perspective. Dermatol Pract Concept. 2016;6(2):3. https://doi.org/10.5826/dpc.0602a03

24. Raghavendra BN and Basha JS. Clinico-histopathological features of lichen planus-an appraisal. Perspect Med Res. 2016;4(2):34-38.

25. Gerharz DB and Ruzicka T. Pityraisis rubra pilaris. In: Wolff K, Goldsmith LA, Katz SI, Gilchrest BA, Paller AS and Leffel DJ, editors. Fitzpatrick's Dermatology in General Medicine. $7^{\text {th }}$ ed. New York: McGraw Hill; 2008. p. 232-235.

26. Raju CG, Ankur CP, Vaishalli MR and Khushbu MR. Study of clinico-histopathological correlation of papulosquamous disorders at tertiary care hospital. Sch J App Med Sci. 2015;3(3B):1154-1158.

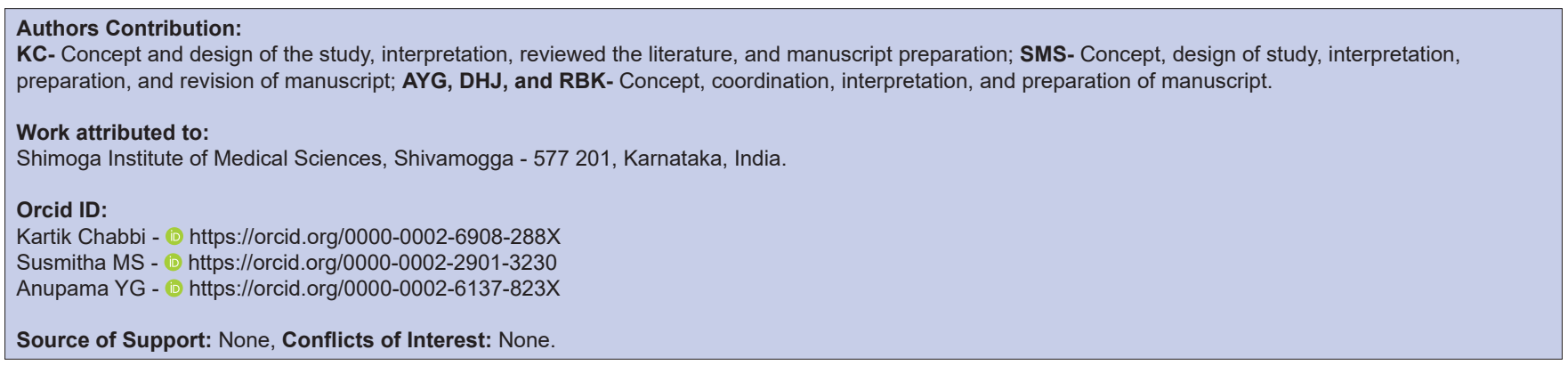

